\title{
Public relations, football and the management of player transgressions in Australia
}

\author{
ERIK TROSBY \\ University of Technology, Sydney
}

\begin{abstract}
Player transgressions have become an increasingly common part of the Australian sporting landscape and can lead to serious reputational and financial damage for sporting organisations, if not managed properly. Using a series of in-depth interviews with media and communication managers across the Hyundai A-League, this study explores how football (soccer) clubs in Australia use public relations strategies and tactics when managing player transgressions. Based on its findings, the study delivers recommendations for public relations practice.
\end{abstract}

\section{Introduction}

Due to a number of scandals relating mostly to the off-field behaviour of coaches and players in the National Rugby League (NRL), 2009 proved to be a challenging year for Australian sport (Smith, 2009). Episodes involving violence and sexual abuse, as well as other antisocial behaviour, produced a serious image problem for the NRL, its clubs and its players (Smith, 2009). The situation also caused concern for stakeholders attached to the code. LG Electronics Australia, for example, opted to terminate their affiliation with the Cronulla Sharks following a controversial case of sexual abuse involving several of the club's players (Prichard, 2009). Furthermore, part owner of the NRL, News Limited, was said to be desperate to end their involvement in the game following growing frustration caused by "continuing conflicts of interest over coverage of player scandals and payment for media rights" (Masters, 2009, para. 1).

While 2009 reaffirmed athlete transgression as a significant problem for Australian Rugby League, it is not a phenomenon exclusive to the NRL or Australia. Indeed, the English Premier League has a history of alcohol abuse and anti-social behaviour among its players. Moreover, at the end of 2009 Tiger Woods took an indefinite break from golf after admitting to a series of infidelities (Ferguson, 2009; Leonard, 2009). Consequently, athlete transgression is increasingly considered to be a global issue in sport (Chadwick, 2009; Eccleston \& Millward, 2006; BBC Sport, 14 Dec. 2001; Lakasing \& Mirza, 2009). Common to such transgressions however, is the detrimental impact they have on an athlete's or organisation's relationship with important publics such as investors, sponsors, fans and broadcasters (Bruce \& Tini, 2008; Fortunato 2008; Wilson et al., 2008). Causing damage to corporate and brand reputations, transgressions also provide fiscal damage and, as duly illustrated in the case of the Cronulla Sharks, compromise an entire organisation's financial well being (Byrnes \& Phelps, 2009; Prichard, 2009; Wilson et al., 2008). The scandals caused by professional athletes' off-field behaviour have increased both public and media scrutiny. As such, they have highlighted the need for sports organisations to employ both proactive and reactive measures to effectively manage a range of internal and external public relations issues. 
The Hyundai A-league and Football Federation Australia (FFA) have not been immune to player transgressions. In 2009 FFA suspended a Sydney FC player after it was revealed that he had engaged in a sexual act with a 13-year-old girl (ABC News, 15 May 2009). It is assumed that the ongoing appearance of such incidents, accompanied by stonewalling strategies, could lead to a serious reputational crisis for any sports organisation (Smith, 2009; Stoldt et al., 2006). It is therefore imperative that clubs in the Hyundai A-league learn from the mistakes of other codes and prepare for potential scandals, as they have resulted in negative publicity, loss of sponsors and damaged reputations among key publics (Bruce \& Tini, 2009; Smith, 2009; Wilson et al., 2008).

This study examines the Hyundai A-league clubs and their management of player transgression issues through the use of public relations strategies and tactics. Furthermore, based on its findings, the study seeks to identify practical implications and recommendations for sports public relations practice.

\section{Literature Review}

\section{Transgressionary behaviour in sport}

Stoldt et al. (2006) argue that the most widespread type of crises in American professional and college sport is related to athletes' off-field behaviour. As Tiger Woods, the Benetton Formula One team, and the T-Online professional cycling team all demonstrated in 2009, transgressions occur across different sporting codes and are by no means limited to any specific code (Chadwick, 2009). Although transgressionary behaviour and activities occur in different sporting codes and may vary in nature, they also carry similarities. Generally speaking, to transgress is to, "infringe or go beyond the bounds of a moral principle or established standard of behaviour" (New Oxford American Dictionary, 2009). As such, a transgression can also be labelled as a "violation of the implicit or explicit rules guiding relationship performance and evaluation" (Aaker et al., 2004).

Chadwick (2009) contends that in sport the established standards of behaviour or bounds of moral principles are not necessarily driven by what is generally considered to be "socially or morally right or wrong" but rather what is recognised as being "commercially acceptable or unacceptable" (para. 21). Highlighting Tiger Woods' off-field behaviour, Chadwick (2009) predicts that the world of sport will also expand contractual terms relating to transgression, as important brands move to safeguard their multi-million dollar investments.

\section{Alcohol and sport}

As transgressionary behaviour is considered a serious issue in professional sport, numerous studies have sought to identify the cause of the problem. A review of relevant literature suggests that there is more than one factor that generates offensive behaviour among athletes. However, alcohol is consistently cited alcohol as a key factor.

Munro (2000) states that Australia is a model case where alcohol and sport are united in a close partnership. However, many researchers perceive this to be a problematic relationship. O'Brien et al. (2008), for example, observe that 'hazardous drinking, including binge drinking and frequent binge drinking in New Zealand university sportspeople is high for both males and females' (p.1). A different study of the pattern of alcohol consumption amongst high school and college athletes and non-athletes in the US found that non-athletes were using less alcohol and engaging less frequently in alcohol-related "risky" behaviours 
(Hilderbrand et al., 2001). Yusko et al. (2008) likewise find that athletes engaging in frequent episodes of heavy drinking are likely to experience negative consequences resulting from such use. Similar studies echo this finding, stressing the negative effects excessive alcohol consumption on athlete behaviour (Anderson et al., 1991; Martens et al., 2003; O'Brien \& Lyons, 2000).

O'Brien and Kypri (2008) further argue that the alcohol industry's sponsorship of athletes is associated with hazardous drinking behaviour. The Preventative Health Taskforce, a government body that provides evidence-based information on policies and programs to prevent alcohol-related harm in Australia, raises similar issues in a 2009 report. The report assumes that the relationship between alcohol-related marketing, promotion and sport is a negative one (Preventing Alcohol-related Harm in Australia, 2009). Related studies undertaken in other countries appear to confirm these findings, noting that bans on alcohol advertising in western societies decrease alcohol consumption among adults and adolescents (Atkin, 1992; Saffer, 1991; Saffer \& Dave, 1996; Saffer \& Dave, 2002).

\section{Masculinity and sport}

While many studies have focused on the connection between alcohol, sport, and transgressionary behaviour, others have examined transgression in sport from a different perspective. For Burgess et al. (2003), sport in Western societies promotes a desired type of masculinity that emphasises strength, courage and power. Such ideals have therefore become constitutive of "true" maleness. Furthermore they contend that:

footballers are established as real men and made knowable as particular selves through their repetitive involvement in sporting confrontations. Even in sports where the display of violence is not so overtly manifested, participants are able to signify their masculine authenticity through performances that suggest the threat of violence (p.210).

Such ideas imply that certain athletes are prone to be violent due to the nature of the sport they play, and the cultural milieu that is structured through the athlete's involvement in that particular sport.

\section{Culture}

Elaborating on the discussion of culture, Light and Kirk (2000) argue that sport is a cultural practice that enhances gender inequality and reproduces a male hegemony and gender order, which in turn "reinforces historically constructed relations of power between men and women that privilege men over women" (p. 174). Several other researchers add that sport similarly plays a significant part in creating a negative and abusive masculine culture among male athletes (Burgess et al., 2003; Moroney, 1998; Wedgwood, 2003; Welch, 1997; White et al., 1992).

The apparent emergence of this cultural phenomenon in Australia has also received growing attention from mainstream media outlets (Barrett, 2009; Jackson, 2009; Toffoletti, 2007). Warren (2002) therefore speaks of a troublesome 'closed shop' mentality that exists in certain sports administrations in Australia, and warns that

given the strength of male culture within elite sports administration, it can be extremely difficult for both outsiders, and insiders, to criticise how these organisations undertake business and development projects' (p.19). 
This 'closed shop' mentality has seen the Australian NRL branded as "the code of silence" (Four Corners, 2009). Ultimately, Smith (2009) concludes that the behaviour shown in the NRL indicates that the code is out of synch with Australian society.

\section{Transgressionary behaviour - a global phenomenon}

The issue concerning transgressionary cultures in male-dominated team sports is by no means purely an Australian phenomenon; alcoholism and binge drinking have haunted professional football in England for years (Collins \& Vamplew, 2002; Eccleston \& Millward, 2006; BBC Sport, 14 Dec. 2001; Vamplew, 2007). News media often portray alcohol abuse and transgressionary behaviour as something of a new phenomenon in modern sport and an inevitable consequence of the wealth enjoyed by English footballers. However, Lakasing and Mirza (2009) contend that "football and alcohol have a longer, more complex and more international relationship than is usually acknowledged" (p. 78). The cultures of binge drinking and deviant sexual behaviour among professional footballers have similarly been identified as an issue in South Africa (Tau, 2009). American findings display similar patterns with various studies identifying college student-athletes as a high-risk group for heavy alcohol consumption and transgressionary behaviour (Martens et al., 2003; Wheeler et al., 2001).

\section{$P R$, sport and transgressionary behaviour}

Unlike the relationship between alcohol, masculinity and transgressionary behaviour in sport, the impact of the relationship between public relations issues and transgressionary behaviour in sport have largely gone unnoted. Wilson et al.'s (2008) inquiry on player transgression and the management of sport sponsor relationships develops a conceptual model to explain the relationships between key elements related to player transgressions and subsequent sponsor responses. In the US, Fortunato (2008) provides a comprehensive case study of Duke University's image restoration and response strategies following a sex scandal involving several student athletes. He argues that "the public relations philosophies of both persuasive advocacy and relationship management have value in confronting a crisis situation" (p.121). Based on a textual analysis of media coverage of a rugby league salary cap scandal in Australasia, Bruce and Tini (2008) argue that, in certain situations, a sports organisation may draw upon a crisis response strategy, which the authors label "diversion", in order to successfully limit the damage to the organisation's reputation. The common denominator in these studies is the centrality of media relations. Underscoring its prevalence, Desmarais and Bruce (2008) note that

professional sport is an unusual public relations field in that the mass media plays a pivotal role in how a sport is perceived by its publics. As a result, the public image of the sport is largely out of its direct control (p. 1).

Reaffirming criticism of the two-way symmetrical approach to public relations that holds it to be naïve and imperfect, Wilson et al. (2008) claim "the two-way symmetrical approach is not appropriate in all aspects of managing player transgressions" (p. 105). They suggest that the conflicting objectives and timeframes that may exist in the relationship between the sport organisation and the media problematise such an approach. 


\section{Defining Crisis}

Public relations research has focused on the relationship between player transgression and crisis management. This focus is logical if one subscribes to Helitzer's (2000) supposition that "there is a potential crisis brewing inside every event, because sports off the field are as unpredictable as each play on the field" (p. 93). More recently, Cutlip et al. (2006) identify a crisis as

a low probability, high impact event that threatens the viability of the organisation and is characterised by ambiguity of cause, effect and means of resolution, as well as by a belief that decisions must be made swiftly (p. 326).

Furthermore it is believed that a crisis is often unexpected, usually disruptive and typically generates allegations, which are incorrect, unfavourable and harmful for the sports organisation (Stoldt et al., 2006). The importance of organisational preparedness and strategic thinking in crisis management is highlighted by Carmeli and Schaubroeck (2008), who state that "crisis situations suddenly shine a spotlight on any problem in the design and activities of an organisational system" (p. 178). Moreover they argue that a majority of crises situations occur because management are caught out by foreseeable events, again highlighting the need for environmental scanning processes (Carmeli \& Schaubroeck, 2008, p. 178). It is therefore considered imperative to develop and implement strategic processes such as crisis planning and forecasting in order to protect an organisation's reputation (Haywood, 2005, p. 233).

Fortunato (2008) asserts that an organisation that has been struck by a crisis must employ communication initiatives in order to rectify the situation and rebuild organisation-public relationships, and show it still complies with acceptable behaviour (p. 118). Benoit (1995) identifies five reactive strategies that an organisation may implement in times of crises. The denial strategy neglects the crisis and offers simple denial in regards to the incident in question. The evasion strategy attempts to reduce responsibility. A third strategy focuses on reducing the offensiveness of the act by highlighting the good traits of the organisation. The corrective action strategy tries to solve the problem and prevent it from happening again whilst the mortification strategy sees the organisation take full responsibility for the crisis and delivers an apology. In order to be in a position to handle potential crises situations, organisations must be able to implement any or all of these strategies at short notice.

\section{Relationship management}

Relationship management is another concept relevant to a discussion of public relations and the management of transgressionary incidents (Ledingham, 2003). Certain scholars have argued that popular public relations ideas, such as the two-way symmetrical approach, are "not appropriate in all aspects of managing player transgressions" (Wilson et al., 2008, p. 105). However, it is also assumed that an organisation with well-developed relationships prior to a crisis and the ability to manage to acknowledge and foster these relationships during a crisis, will suffer less financial, emotional and perceptual damage than others (Fearn-Banks, 2002, p. 20). As Hon and Grunig (1999) note

organizations generally make better decisions when they listen to and collaborate with stakeholders before they make final decisions rather than simply trying to persuade them to accept organizational goals after decisions are made (p. 10). 
Public relations professionals are consequently encouraged to take a dialogic stand to communication, both prior to and during a crisis.

Originally conceptualised by human communication theorists, relationship management focuses on shared and balanced interests and continuous dialogue to help foster understanding and collaboration between the organisation and its publics (Ledingham, 2003; Ledingham \& Bruning, 1998). As such, it relationship management provides another perspective on how to manage communication with publics following athlete transgressions.

In an arena where transgressions in sport remain a significant problem and major brands need to protect their multi-million dollar investments from being undermined by scandal, the management athlete and team behaviour has assumed greater importance (Chadwick, 2009). While the broad majority of the public relations literature concurs that crisis planning and communication should be a public relations responsibility, little attention has been given to issues concerning public relations and transgressionary behaviour in sport (Argenti, 2009; Anthonissen, 2008; Cutlip et al., 2006; Fearn-Banks, 2002; Helitzer, 2000; Lee, Woeste \& Heath, 2007; L'Etang, 2006; L'Etang \& Hopwood, 2008; Stoldt, et al., 2006; Tench \& Yeomans, 2006; Toth, 2007). Similarly, a survey of this literature indicates that most studies on public relations and transgressionary behaviour conducted in Australasia focus on NRL, rugby union or AFL. The impact of such issues in football has largely gone unnoted. Moreover, most studies concentrate on the cause of the problem, such as alcohol abuse or the formation of deviant cultures, rather than implications for public relations practice. Some attempts have been made to address crisis management in sports, but to a certain degree the attempts have been somewhat generic. For example O'Beirne and Ries' (1999) sport crisis management model includes all the processes necessary for successful management of crises in sports marketing, however it does not consider football, and has less focus on public relations. Stoldt et al., (2006) similarly deliver a comprehensive guide on how to manage transgression incidents and issues in sport, but no specific reference to football is made. Hence, as transgressionary behaviour in sport is increasing as a global phenomenon (and certainly an Australian phenomenon), this study intends to address this gap in the literature, and thus explore how clubs in the Hyundai A-League manage the associated public relations issues.

\section{Methodology}

The research was based on in-depth interviews with media and communications managers from eight of the ten existing Hyundai A-league clubs. For the purpose of this study, it was decided that in-depth interviews would be conducted as such techniques provides insights and opinions, which deliver a deeper understanding of why certain attitudes and behaviours exist among the participants (Stacks, 2002; Yin, 2009). In addition, it was anticipated that indepth interviews would provide early warning signs on important issues (Cutlip et al., 2006). The method would only provide a snapshot of today's state of affairs, as many participants as possible (eight out of ten) were included to provide broad data. However, it could indicate trends relating to attitudes and behaviours within the league (Bryman, 2004).

Exploratory research indicated that there was no individual person that held all PR responsibilities in Australian football clubs. Although there were no managers that strictly managed PR in any of the clubs in question, the media and communication managers were believed to carry most of the PR responsibilities for their organisations. It was assumed that the media and communication managers would have an overview of all the communication aspects in the organisation because of their position in the club (Cutlip et al., 2006). Media 
and communication managers were chosen as the interview participants under the assumption that they would be the most capable representatives to cast important light on how organisations managed transgressionary incidents.

The interviews were semi-structured, with open-ended and topical questions, which allowed the interviewees to elaborate on their answers and further probing took place when needed (Bryman, 2004). Lastly, the study assumed Yin's (2009) approach, which avoids leading questions, and instead carefully words the questions so the interviewer appears genuinely naïve so as to permit the interviewee to provide fresh commentary about the issue (p. 107). The interviews were analysed and coded for themes in order to create a structure from where findings could be gathered. These themes were then compared and contrasted, and a logical chain of evidence was developed (Miles \& Huberman, 1994).

\section{Findings}

The participants in this research were media and communication managers from eight of the ten Hyundai A-League clubs. Responsible for public relations activities mainly relating to media relations, most of the managers came from journalism, with a variety of backgrounds and experiences. They all shared a common focus on catering for the media and the idea of the media as one of the organisation's most important publics. The participants' backgrounds might explain why they were more focused on media relations than other public relations and communication activities. However, a contributing factor might also be Desmarais and Bruce's (2008) idea of professional sport as an unusual public relations field insofar as the mass media plays a pivotal role in the way that the sport is perceived by its publics. As such, the public image of the sport is, to a great extent, out of the organisation's direct control. In general, the participants had limited experience with crisis management in their clubs, although one practitioner did have extensive experience from the health industry. The degree of insight offered by each respondent differed, revealing varying levels of experience. Useful conclusions nevertheless emerged from the interviews, and six key findings were drawn from this research.

\section{Transgression as an organisational problem in football.}

All the participants agreed that transgression, as witnessed in the NRL or as a broader societal problem, was serious and unsought. However, a significant finding was that several of the respondents were rather relaxed about transgression in football. Although a majority of the participants had experienced transgressionary behaviour in their clubs at some point, they did not perceive player transgression to be a problem in their organisations. The relevant participants explained that this moderate attitude was due to the belief that player transgression was rare in the Hyundai A-league, and that their players were aware of what kind of behaviour the club expected from them and acted accordingly. Despite the sense that player transgression was a rarity in the A-League, two participants were still adamant that isolated incidents were inevitable. One of explained that trying to control the almost 200 players that feature in the A-league is an impossible task. The second concurred, explaining that it was difficult to be a hundred per cent secure against transgressions taking place because "people are people" and each individual has a different background. Although this participant possessed the greatest experience in crisis communication, this media and communication manager also expressed the surprisingly lax view that crisis plans were not a necessary tool when managing a crisis scenario. He argued against the preparation of standardised plans and scenarios due to the amount of variables inherent in each incident. 
Although many of the participants had previously experienced transgressionary behaviour in their clubs, they did not view transgressionary behaviour as a cause for concern. Compared to the NRL and AFL, where transgressionary behaviour has caused great concern for communication managers, the moderate attitudes found in the Hyundai A-League indicate three things (Wilson et al., 2008). Firstly, certain football clubs might be vulnerable and unprepared in the event of a major transgressionary incident. Secondly, transgressionary behaviour is so rare in football compared to other codes that the media and communication managers put the occasional incident down to the natural order of things - a point that was raised by the most experienced participant. Thirdly, the managers are confident and comfortable with the existing culture among their players, in their clubs and in the Hyundai A-League. The existence of this culture also represents the second finding from this research.

\section{Culture}

While the media and communication managers held different views in relation to the importance of player transgression, the majority highlighted the creation of a positive culture amongst the players as a fundamental way of preventing transgressionary behaviour. Some practitioners argued that the 'culture' and 'climate' in football was unique in that most football players did not engage in the party and binge drinking cultures found in other codes. One media and communication manager who did not view transgression in football as a particular problem suggested that the differences stemmed from a social phenomenon. Football was labelled a white-collar sport, as opposed to a blue-collar sport, and therefore had a different 'party culture' and relationship with alcohol. Furthermore, a second participant claimed that many of their players were family oriented, with "other priorities than to bingedrink".

This presumed cultural phenomenon or difference among Hyundai A-League clubs contrasts markedly with the situation in England, where football traditionally has been a blue-collar sport and often associated with a heavy drinking culture (Lakasing \& Mirza, 2009). Cultures of heavy drinking and deviant sexual behaviour can also be found in South Africa, where there has been a range of alcohol related problems associated with football (Tau, 2009). Such comparisons indicate that football has developed a unique culture in Australia. In other parts of the world, such as England, 'footballers are not considered good role models' (Hopwood, 2009, pers. comm., 18 March). Lastly, these findings also suggest that culture is a major determinant of transgressionary behaviour in sport, which indicates the need for a constant focus on positive culture creation and education.

Many of the participants stressed the importance of the clubs' internal education programs. One respondent explained that the education programs focused on making players aware of their responsibilities, what kind situations could put them in harm's way, and the consequences of their actions. The respondent who did not value crisis planning in relation to player transgressions stated that "it's all about education and that is the absolute best we can do". A third media and communication manager also praised the educational programs established by the FFA and the Hyundai A-League to teach players about social responsibility and being a role model. Most of the participants felt that their efforts to educate players were successful and that it had a positive impact on the players' behaviour. It was also felt that such education produced a positive mindset and culture in the respective clubs. Respondents frequently mentioned how senior players in the club were important role models who could spread educational messages to the rest of the players. To support their educational initiatives, most of the clubs had a formalised code of conduct and/or policy with 
which the players had to comply when signing for the club. These were either put in place by FFA and the Hyundai A-League or the club itself.

\section{Relationship building in the community}

The third finding described the media and communication managers' focus on fostering positive relationships with key publics in the community. Stressing relationship building as an effectual tactic to gaining a competitive advantage, one participant said that "the importance of going out and engaging the stakeholders is absolutely imperative for us". Another participant explained that their public relations efforts were "all about relationships". Moreover, one manager stressed the positive impact stakeholder involvement could have on the club's reputation and the significance of maintaining a good reputation. "Without your reputation", he declared, "you've got nothing".

Many respondents mentioned how the trust and goodwill that the organisation had established with stakeholders prior to an undesirable incident, could potentially soften the impact of a crisis and potentially "shave off some of the after effects". However, two media and communication managers believed, that if a serious transgression took place, e.g. sexual assault, the status of relationship would not matter as much, due to the gravity of the transgression. Furthermore, the relationship-building efforts in place varied considerably. Half of the respondents admitted that the focus on relationship building in the community had not been of the highest priority in the past, but they were currently looking at increasing these efforts in the future. Fostering good relationships with the media was of the greatest importance to all respondents.

This finding indicates that the some of the participants value proactive public relations tactics as a suitable way to foster relationships and to limit potential negative consequences relating to issues within the club. Such ideas correlate with the ideas espoused in Ledingham's (2003) relationship management theory. They demonstrate that some of the practices in the Hyundai A-League are not merely limited to reactive initiatives, but also include an appreciation for proactive approaches as a strategic instrument in the quest for competitive advantage.

\section{Relationship building with the media}

All participants reported that their relationships with the media were mainly positive, although one media and communication manager felt that the media could be obtrusive. Some respondents also indicated that there were still elements in the media that were negative to football as a sport in Australia, which could be particularly challenging in times of crisis. One participant contributed this negative attitude to the fact that News Limited has significant ownership interests in the NRL, its clubs and its broadcasters. Such connections were seen to have an impact on the editorial priorities of certain news media, making the battle for space in the media more challenging. Some respondents also mentioned that it was a struggle to receive the desired amount of media space due to heavy competition with other codes. Conversely, other participants were satisfied with the amount of positive attention their clubs gained from the media and the relationship they enjoyed with journalists. It is noteworthy, that this notion differed depending on the geographical location of the football clubs, and thus the amount of competition for media space other codes provided.

Community work and relationship building initiatives with fans, especially at a grassroots level, were popular strategies among the clubs involved in the study. However, the interesting aspect to the findings was that the participants were extremely concerned with maintaining 
good relations with the media. Given the amount of attention news media provide sports in general, this might seem obvious. However, it is also important to consider the importance of other relationships, particularly in times of crisis when the media attention may not be as desirable. This issue will be discussed further in the recommendations at the end of this article.

\section{Preparedness}

The reactive measures in place varied considerably between the different clubs. A majority had readied formalised crisis plans and procedures. Those that did not pointed out that it is difficult to prepare standardised plans and scenarios due to the amount of variables inherent in each incident. This moderate attitude was linked to the fact that some of the participants did not view player transgression as a problem in Australian football. However, the clubs that did not have formalised plans did have "informal procedures" to deal with difficult situations and expressed that they were satisfied with this approach as it had been successful in the past.

This view may have indicated that some of the organisations were potentially naïve, vulnerable and unprepared for potential crises. Two different examples brought forward by the participants illustrated this concern, as one participant said he had been forced to employ the club's formalised procedures when a player was involved in a scuffle at a restaurant. However, it was reported that the implementation of these procedures was successful. Furthermore, he explained that he had felt in control of the issue and was able to manage the situation in a manner which did not harm the club's reputation or relationships. This was much due to the existence of pre-planned procedures which gave instructions as to how the issue should be handled.

This contrasted with the experience of a media and communication manager at another team, where formalised crisis plans and procedures did not exist. He explained that there had been an incident at the club involving one of their players where he felt they lost control of the communication and, in particular, the media coverage. It was conceded that in hindsight things could have been managed differently had they been better prepared, indicating the need for preparation in issues and crisis management. The participant was also insecure and had difficulties explaining why such plans did not exist. Although he stated that he did not need a crisis plan as transgressions rarely occurred, he nevertheless saw the benefit based on the previous example he gave. The participant also gave an impression that the club could be vulnerable should a major scandal involving transgressionary behaviour occur, a situation which is potentially very dangerous for the organisation.

\section{Win the disclosure race}

Closely related to the discussion on reactive crisis management were the issues concerning promptness in crisis situations. All the respondents agreed that it was important to act swiftly in times of crisis. As one respondent explained, such speed was needed in order to "win the disclosure race". Based on a hypothetical example of a serious transgression where a player was arrested, the same respondent estimated that an organisation would usually have about two hours before the media started asking questions. This highlighted the immediate need to control the media and media messages. Furthermore, he explained that:

you have to be the first to tell in that situation because then you're at least seen as a reliable source of information and a honest source of information and the media won't look elsewhere for qualification of the story if they believe what they get from you is correct and proper. 
His counterparts at the other clubs agreed that honesty and openness in a timely manner was key when handling problematic situations. One respondent claimed that "it's better to tell it all at once because the media will find out everything anyway and there is no reason to hide the obvious". Another participant concurred, saying it was better that they heard it from the club rather than other sources. Furthermore, this respondent believed that a quick and honest response from the organisation would shorten the 'life' of the issue or crisis, and media interest would consequently die off sooner rather than later. Some participants also pointed out that other stakeholders such owners, sponsors and investors should be kept in the loop early on in times of crisis.

It was interesting to discover that while some of the respondents were extremely conscious of the need to act swiftly in times of crisis, the same respondents did not see the value of formalised crisis plans. This appears to be at odds with the view that crisis plans and procedures faciliate the communication process in times of crisis and help the crisis manager make quick and well-informed decisions in a short space. Moreover, it is supposed that those who operate without such procedures may be vulnerable in a situation when communication should be swift (Stoldt et al., 2006). The attitudes found in some of the organisations therefore appeared to contradict some academic theories and may indicate that some media and communication managers were somewhat naïve and unprepared for situations demanding speedy responses - in spite of the fact that they appreciated the need for swift communication in times of crisis.

\section{Recommendations and implications}

\section{Culture and the importance of educational programs}

A significant finding from this study is the idea of culture as a key determinant of transgressionary behaviour in sport. Football in Australia is seen to possesses unique cultural attributes that differ from competing codes on a national level and to football cultures internationally, such as those in England and South Africa. To this end it ,is recommended that extensive work is directed at the creation of initiatives which enhance positive cultures in sports organisations, based on socially acceptable values, attitudes and principles.

A common theme in this study has been the need for sports organisations to educate players about their responsibilities as professional football players. All the respondents that had education programs in place felt that their players understood their responsibilities and acted accordingly. It also seemed to create a positive culture within the clubs and the sporting code in general. The low number of transgression incidents in the Hyundai A-League also indicates that this approach is effective. This view is supported by Wilson et al., (2008), who suggest that crisis prevention initiatives, such as education programs, could be an effective strategy to create a positive culture among players, and consequently prevent transgressions.

\section{Foster relationships with key publics}

Several scholars agree that the true value of public relations lies in relationships, and that a fundamental goal of the discipline is to build, maintain and enhance on-going or long-term relationships with an organisation's key publics (Hon \& Grunig, 1999; Hopwood, 2007; Ledingham, 2003; Ledingham \& Bruning, 1998). By opening the organisation to publics and fostering organisation-public relationships based on mutual benefit, Hon and Grunig (1999)

Public Communication Review, Vol. 1, No. 2, 2010. 
suggest that the outcome will deliver enhanced commitment, satisfaction and trust between the organisation and its stakeholders.

Hobbs (1995) argues that in a crisis situation, the organisation-public relationship is damaged. Coombs therefore suggests that

treating crisis as just one incident within a longer, ongoing relationship can be an effective approach to understanding and managing these episodes as they provide a valuable context within which to view the relationship (Wilson et al., 2008, p. 100).

To some extend, the participants in this study also express this notion. Several of the media and communication managers identified relationships as key to the survival of the organisation, both prior to and following an issue or crisis. It was believed that existing positive relationships could potentially shave off some of the after effects of a crisis. This idea also correlates with Ledingham's (2003) view that stakeholders who understand why an organisation is behaving in a certain way is likely to also accept this behaviour. The belief that ongoing communication about the club's crisis management could have positive effects on organisation-public relationships suggests that organisations should inform key publics, such as sponsors, investors, and governing bodies, of the ways that particular crisis scenarios are to be managed within the organisation - both prior to and during a crisis (p. 104). Such a dialogue can also be established with other stakeholders, to an appropriate extent, without disclosing sensitive information. The logic behind this recommendation is based on the idea that if stakeholders understand why an organisation is behaving in a certain way, it is likely that they will also accept this behaviour (Ledingham, 2003).

\section{Media relations}

The participants in this study and the literature all agree the media is one of the main publics in sport public relations. Stoldt et al., (2006) warn that "dealing with the media is often the most important and most difficult aspect of the crisis communication process" (p. 180). Hopwood (2006) suggests that public relations professionals should approach their media management, not only as streamlining communication between the organisation and the media, but rather focus on building relationships with journalists in order to foster a mutual collaboration. The trust and collaboration that is established prior to an issue or crisis, will consequently make it easier to effectively communicate with the media in difficult times and thus ensure that the incident is reported accurately. However, Wilson et al., (2008) suggest that although public relations practitioners should strive to establish mutually beneficial relationships with the media that are based on open flow of communication and shared power, this approach is not always appropriate due to conflicting objectives and timeframes in times of crisis (p. 105). In that regard, it is imperative to remember that negative news stories, such as those related to transgressionary behaviour, can seriously damage the reputation and popularity of an organisation and affect the bottom line in areas such as attendance, merchandising, sponsorship and endorsement deals (Shilbury, Quick \& Westerbeek, 1998). It is therefore recommended that clubs focus not only on media relations, but also put effort into building long lasting relationships with other stakeholders such as fans, sponsors, governing bodies and local communities on a more personal level. In that respect, community work, open training sessions and events directed at other stakeholders than just the media can be suitable.

Lastly, the media and communication managers stressed the need to act swiftly in a crisis. History has proven that organisations that fail to recognise the need to act quickly tend to 
further deteriorate the crisis (Argenti, 2009, p. 281). This is particularly relevant when addressing the media. Arpan and Roskos-Erwoldsen (2005) describe the "stealing thunder strategy" in which organisations proactively declare that there has been a serious incident that is of interest to the public and likely to come out anyway. This strategy has proven to be highly effective and is something practitioners should consider. In many cases, the strategy will increase the organisation's credibility and diminish the impact on reputations. Furthermore, it allows the organisation to prepare and set the tone for the coverage of crisis. It is advised that an expert is engaged to help with the preparation and implementation of such strategies (Arpan \& Roskos-Erwoldsen, 2005).

\section{4. $\quad$ Prepare for crisis situations}

Although professional sports organisations operate in a context where it would seem logical to have well-developed crisis communication plans, it appears that many sports organisations, including those with professional full-time staff, continue to operate in a reactive or ineffective fashion rather than planning and preparing for the kinds of crises that can be predicted (Helitzer, 1999; Marra, 1998). Cutlip et al., (2006) stress that the "key to anticipating and avoiding crises is assessing what can go wrong, what can affect people or the environment, and what will create visibility" (p. 328). Regardless, research still proves that a majority of crises situations occur because management are caught out by foreseeable events (Carmeli \& Schaubroeck, 2008). However, some incidents will inevitably shine a spotlight on the organisation, and it is this unexpected visibility that can turn issues into crises that threaten reputations, credibility and market positions. It is those who are quickly able to adapt to this new situation that survive (Carmeli \& Schaubroeck, 2008; Cutlip et al., 2006, p. 327).

Stoldt et al., (2006) stress the importance of having ready-made plans and procedures that every member of the organisation is aware of in order to ensure that everyone knows what to do if problematic issues should occur. It was therefore surprising to discover a degree of reluctance towards the use of crisis plans among some participants. This might potentially create problems for organisations that have little experience with crisis management. To address this somewhat nonchalant and naïve attitude, this study argues that may differ but many situations do carry similar characteristics. Therefore, the organisation should not entirely rely on a detailed crisis plan, but rather use the plan as a foundation for how they approach crises. Having established procedures on how to manage the initial phase of a crisis (i.e. establishing a crisis communication committee, establishing initial communications, defining key stakeholders etc), it is likely that the organisation can "buy time" and be even more flexible in their crisis management (Stoldt et al., 2006). Such planning would help an organisation control communication from day one rather than being forced to play catch up, as one participant reported to have experienced (Fearn-Banks, 2002).

\section{Conclusion and limitations}

This study has described how clubs in the Hyundai A-League use public relations strategies and tactics when dealing with player transgression issues and potential crises. In doing so, it has also illuminated an area that has received scarce attention at both national and international levels. Research has revealed how public relations is prioritised and structured in the day-to-day operations of the participating clubs, with media relations and publicity being the main focus.

The study describes a sporting code where the attitudes towards transgressionary behaviour as an organisational concern varied considerably. As such, the level of organisational crisis 
preparedness also differed substantially. The fact that few football clubs viewed transgressionary behaviour as a concern may indicate that some clubs are unprepared in the event of a player transgression. However, it also suggests that player transgression is less of a problem in football compared to other codes and countries. Nevertheless most participants in this study reporting that isolated incidents had occurred in their organisations.

A distinct difference between isolated incidents and evidence of systematic transgressionary behaviour was found. As some participants in this study suggested, there seem to be fundamental cultural differences between football and the competing national codes, namely NRL and AFL. Additionally, this study also indicates that there are cultural differences between football in Australia and other countries, such as England and South Africa, where alcohol related transgressions are more common. The reasons for these cultural differences are unclear, and it is highly recommended that this phenomenon is researched further, especially in relation to masculinity, anti-social behaviour and alcohol abuse. Case study comparisons of sports codes, and transgressionary incidents and cultures within those codes are encouraged, as are comprehensive ethnographic studies to identify factors or attributes that may help explain those transgressionary behaviours and cultures. Further, quantitative testing of those factors and attributes would enable researchers to ascertain with greater certainty, what determines transgressionary behaviour.

As this research only considers the views of the media and communication managers in certain clubs, further research into how transgression affects the attitudes and behaviours of external and internal publics and stakeholders is encouraged. In order to anticipate the consequences of such transgressions, further investigation into the impact of player transgression on reputations and relationships needs to be undertaken.

Although the theoretical knowledge of public relations seemed scarce amongst the participants, it was remarkable to discover that many of their reflections correlated with popular theoretical concepts such relationship management. As most football administrations in Australia are small, many people in the organisation share the public relations responsibilities. This indicates a need for a high level of communication management skills among top managers. This is particularly important, as many of the media and communication managers focus their attention on catering to the media. In this respect, external public relations consultation may be enhance the strategies of many of the organisations that participated in this study.

A largely exploratory study, this research only provides a generic and somewhat superficial overview of the status quo in the Hyundai A-League, hence the results should be viewed with some caution. However, the study does indicate the priorities of the respondents and why they use public relations to manage transgression the way they do. It also sheds important light on cultural differences, on both a national and international level, which should be explored further. In light of crisis management, the study reveals that organisational preparedness varied considerably, and indicates that some organisations may be vulnerable to reputation crises.

Finally, the author of this paper shares L'Etang and Hopwood's (2008) concern that the attention given to sports public relations is somewhat sporadic and scarce, regardless of the critical function that public relations have in sport (L'Etang, 2006; Wilson et al., 2008, p. 100). As "sport is a unique 'product' in that many of its messages and images are conveyed through media coverage rather than through advertising or sales campaigns", it is also likely that public relations plays an important strategic role in any successful sporting organisation 
(Bruce \& Tini, 2008; Hopwood, 2007). However, its effectiveness has been hampered in some areas by the lack of understanding regarding the strategic importance of the discipline (Hopwood, 2006 in Wilson et al., 2008).

\section{References}

Aaker, J., Fournier, S., \& Brasel, A. S. (2004). When good brands do bad. Journal of Consumer Research, 31(1), 1-16.

ABC News. (2009, May 16). A-League player faces child sex charges. Retrieved from ABC News Website: http://www.abc.net.au/news/stories/2009/05/15/2571736.htm.

Anderson, W.A., Albrecht, R.R., McKeag, D.B., Hough D.O. \& McGrew, C.A. (1991). A national survey of previous alcohol and drug use by college previous athletes. Physician and Sports Medicine, 19, 91-104.

Anthonissen, F. P. (Ed.). (2008). Crisis communication: Practical PR strategies for reputation management and company survival. London: Kogan Page Ltd.

Argenti, P.A. (2009). Corporate Communication ( $5^{\text {th }}$ ed.). New York: McGraw Hill-Irwin.

Arpan, L. M. \& Roskos-Ewoldsen, D. R. (2005). Stealing thunder: Analysis of the effects of proactive disclosure of crisis information. Public Relations Review, 31(3), 425-433.

Atkin, C. K. (1992). Survey and experimental research on alcohol advertising effects. Paper presented at the National Institute of Alcoholism and Alcohol Abuse conference on Alcohol and the Media, Washington, DC.

Barrett, R. (2009, May 8). Matthew Johns in group sex scandal. Retrieved from ABC News Website: http://www.abc.net.au/news/stories/2009/05/07/2563957.htm.

BBC Sport (2009, December 14). Football's booze culture. Retrieved from BBC Sport, http://news.bbc.co.uk/sport2/hi/football/1235948.stm.

Benoit, W. L. (1995). Accounts, excuses, and apologies: A theory of image restoration strategies. Albany, NY: State University of New York Press.

Bruce, T. \& Tini, T. (2008). Unique crisis response strategies in sports public relations: Rugby league and the case for diversion. Public Relations Review, 34(2), 108-115.

Bryman, A. (2004). Social research methods $\left(2^{\text {nd }}\right.$ ed.). New York, NY: Oxford University Press.

Burgess, I., Edwards, A. \& Skinner, J. (2003). Football culture in an Australian school setting: the construction of masculine identity. Sport, Education and Society, 8(2), 199-212.

Byrnes, H. \& Phelps, J. (2009, May 21). Major sponsor pulls plug on the Cronulla Sharks. The Daily Telegraph. Retrieved from http://www.dailytelegraph.com.au/sport/nrl/major-sponsor-pullsplug-on-the-cronulla-sharks/story-e6frexrr-1225713946343.

Carmeli, A. \& Schaubroeck, J. (2008). Organisational crisis preparedness: The importance of learning from failures. Long Range Planning, 41(2), 177-196.

Chadwick, S. (2009, January 12). The business of sport - predictions for 2010. Reuters UK, Retrieved from http://blogs.reuters.com/great-debate-uk/2009/12/31/the-business-of-sport-predictions-for2010/.

Four Corners. (2009, May 11). Code of silence [Television program]. Sydney: ABC TV.

Collins, T. \& Vamplew, W. (2002). Mud, sweat and beers: A cultural history of sport and alcohol. New York, NY: Berg.

Coombs, W. T. (2000). Crisis management: Advantages of a relational perspective. In J. A. Ledingham \& S. D. Bruning (Eds.). Public relations as relationship management: A relational approach to the study and practice of public relations (pp. 73-93). Mahwah, NJ: Lawrence Erlbaum.

Cutlip, S.M., Center, A.H. \& Broom, G.M. (2006). Effective public relations ( $9^{\text {th }}$ ed.). Englewood Cliffs, NJ: Prentice Hall.

Desmarais, F. \& Bruce, T. (2008). Blurring the boundaries of sports public relations: National stereotypes as sport announcers' public relations tools. Public Relations Review, 34(2), 183-191.

Eccleston, P. \& Millward, D. (2006, March 3). Peter Osgood, glamour boy of the real man's game. Telegraph. Retrieved from http://www.telegraph.co.uk/news/uknews/1511873/Peter-Osgoodglamour-boy-of-the-real-mans-game.html. 
Fearn-Banks, K. (2002). Crisis communications: A casebook approach. Mahwah, NJ: Lawrence Erlbaum.

Ferguson, D. (2009, December 12). Tiger Woods to take 'indefinite' leave from golf. NZ Herald. Retrieved from http://www.nzherald.co.nz/sport/news/article.cfm?c_id=4\&objectid=10615076\&pnum=2.

Fortunato, J.A. (2008). Restoring a reputation: The Duke Lacross Scandal. Public Relations Review, 34(2), 116-123.

Haywood, R. (2005). Corporate reputation, the brand and the bottom line. London: Kogan Page.

Helitzer, M. (2000). The dream job: Sports publicity, promotion and marketing. Athens, $\mathrm{OH}$ : University Sports Press.

Hobbs, J.D. (1995). Treachery by any other name: A case study of the Toshiba public relations crisis. Management Communication Quarterly, 8(3), 323-346.

Hon, L.C. \& Grunig, J.E. (1999). Measuring relationships in public relations. Gainesville, FL: Institute for Public Relations.

Hopwood, M. (2006). Sports public relations. In J. Beech \& S. Chadwick (Eds.). The marketing of sport (pp. 292-317). Harlow, UK: Prentice Hall.

Hopwood, M. (2007). It's football but not as you know it: Using public relations to promote the world game in Australia. Sport Marketing Europe, 3, 32-37.

Jackson, G. (2009, March 9). Boozy launch may have sunk season. Sydney Morning Herald. Retrieved from http://www.leaguehq.com.au/news/news/boozy-launch-may-have-sunkseason/2009/03/08/1236447048234.html.

Lakasing, E. \& Mirza, Z. (2009). Football and alcohol: A short diary of a long and complex relationship. London Journal of Primary Care, 2, 78-80.

Ledingham, J.A. (2003). Explicating relationship management as a general theory of public relations. Journal of Public Relations Research, 15(2), 181-198.

Ledingham, J.A. \& Bruning, S.D. (1998). Relationship management and public relations: Dimensions of an organization-public relationship. Public Relations Review, 24(1), 55-65.

Lee, J., Woeste, J. H., \& Heath, R. L. (2007). Getting ready for crises: Strategic excellence. Public Relations Review, 33(3), 334-336.

Leonard, T. (2009, December 2). Tiger Woods apologises for 'transgressions' amid new affair claims. Telegraph. Retrieved from http://www.telegraph.co.uk/sport/golf/tigerwoods/6711003/TigerWoods-apologises-for-transgressions-amid-new-affair-claims.html.

L'Etang, J. (2006). Public relations and sport in promotional culture. Public Relations Review, 32(4), 386-394.

L'Etang, J. \& Hopwood, M. (2008). Sports public relations. A special edition of Public Relations Review, 34(2), pp. 87-89.

Light, R. \& Kirk, D. (2000). High school rugby, the body and the reproduction of hegemonic masculinity. Sport, Education and Society, 5(2), 163-176.

Marra, F.J. (1998). Crisis communication plans: Poor predictors of excellent crisis public relations. Public Relations Review, 24(4), 461-474.

Martens, M.P., Cox, R.H., Beck N.C. \& Heppner, P.P. (2003). Measuring motivations for intercollegiate athlete alcohol use: A confirmatory factor analysis of the drinking motives measure. Psychological Assessment, 15(2), 235-239.

Masters, R. (2009, October 8) Why News Ltd is eager to quit the NRL ahead of time. Sydney Morning Herald. Retrieved from http://www.leaguehq.com.au/news/lhqnews/why-news-ltd-is-eager-toquit-the-nrl-ahead-of-time/2009/10/07/1254701061965.html.

Miles, M., \& Huberman, M. (1994). Qualitative data analysis. Thousand Oaks, CA: Sage Publications.

Moroney, B. (1998). Too tough to tackle? Sport, violence, and the social construction of masculinity. In S. Alomes \& B. Stewart (Eds.). High mark: Australian football and Australian culture. Contemporary studies of the great Australian game (pp. 66-75). Hawthorn, Vic.: Maribyrnong Press.

Munro, G. (2000). Challenging the culture of sport and alcohol. International Journal of Drug Policy, 11(3), 199-202.

New Oxford American Dictionary (2009) Oxford, New York: Oxford University Press. 
O’Brien, K. S., Hunter, J., Kypri, K. \& Ajmol, A. (2008). Gender equality in university sportspeople's drinking. Drug and Alcohol Review, 27(6), 659-665.

O’Brien, K. S. \& Kypri, K. (2008), Alcohol industry sponsorship and hazardous drinking among sportspeople. Addiction, 103(12), 1961-1966.

O’Brien K. \& Lyons, J. (2000). Alcohol and the athlete. Sports Medicine, 29(5), 295-300.

O'Beirne, P. \& Ries, S. (1999). Extinguishing the fires: Crisis management in sport marketing. CyberJournal of Sport Marketing, 3(2). Retrieved from http://fulltext.ausport.gov.au/fulltext/1999/cjsm/v3n2/obeirne32.htm.

Prichard, G. (2009, May 13). Nervous Sharks sponsor getting cold feet over player sex scandal. Sydney Morning Herald. Retrieved from http://www.smh.com.au/news/lhqnews/nervous-sharkssponsor-getting-cold-feet-over-player-sex-scandal/2009/05/12/1241893982021.html.

Saffer, H. (1991), Alcohol advertising bans and alcohol abuse: an international perspective. Journal of Health Economics, 10(1), 65-79.

Saffer, H. \& Dave, D. (1996). Studying the effects of alcohol advertising on consumption. Alcohol Health and Research World, 20(4), 266 -272.

Saffer, H. \& Dave, D. (2002), Alcohol consumption and alcohol advertising bans. Applied Economics, 34(11), 1325-1334.

Shilbury, D., Quick, S., \& Westerbeek, H. (1998). Strategic sport marketing. St Leondards, NSW: Allen \& Unwin.

Smith, P. (2009, September 19). Taylor trashed brand. The Australian. Retrieved from http://www.theaustralian.news.com.au/story/0,25197,26093226-12270,00.html.

Stacks, D. (2002). Primer of public relations research. New York, NY: The Guilford Press.

Stoldt, G.C., Dittmore, S.W. \& Branvold, S.E. (2006). Sport public relations: Managing organisational communication. Champaign, Ill.: Human Kinetics.

Tau, A. (2009). Alcohol use and risky sexual behaviour among the South African professional soccer players: implications for life skills intervention programmes. University of Witwatersrand institutional repository, South Africa.

Tench, R. \& Yeomans, L. (2006). Exploring public relations. Essex, UK: Pearson Education Limited.

The Alcohol Working Group. (2008). Australia: The healthiest country by 2020. Technical Report 3. Preventing alcohol-related harm in Australia: A window of opportunity. Canberra: Preventative Health Taskforce, Australian Government.

Toffoletti, K. (2007). How is gender-based violence covered in the sporting news? An account of the Australian Football League sex scandal. Women's Studies International Forum, 30(5), 427-438.

Toth, E.L. (Ed.). (2007). The future of excellence in public relations and communication management: Challenges for the next generation. Mahwah, NJ: Erlbaum.

Vamplew, W. (2007) Alcohol and the Sportsperson: An Anomalous Alliance. Idrottsforum. Retrieved from http://www.idrottsforum.org/articles/vamplew/vamplew070214.html.

Warren, I. (2002). Hyper-masculinity, Super League and corporate governance. In D. Hemphill \& C. Symons (Eds.). Gender, sexuality and sport: A dangerous mix. Petersham, NSW: Walla Walla Press.

Wedgwood, N. (2003). Aussie Rules! Schoolboy football and masculine embodiment. In S. Tomsen \& M. Donaldson (Eds.). Male trouble: Looking at Australian masculinities, (pp. 180-190). Melbourne, Vic: Pluto,.

Welch, M. (1997). Violence against women by professional football players. Journal of Sport and Social Issues, 21(4), 392-411.

Wheeler, J., George H. W. \& Dahl, J. B. (2001). Sexually aggressive college males: Empathy as a moderator in the 'Confluence Model' of sexual aggression. Personality and Individual Differences, 33(5), 759-775.

White J., Garland F., Katz, J, \& Scarborough, K. E. (1992). The impact of professional football games upon violent assaults on women. Violence and Victims, 7(2), 157-171.

Wilson, B., Stavros, C. \& Westberg, K. (2008). Player transgressions and the management of the sport sponsor relationship. Public Relations Review, 34(2), 99-107.

Yin, R. (2009). Case study research: Design and methods ( $4^{\text {th }}$ ed.), Thousand Oaks, CA: Sage Publications. 
Yusko, D., Buckman. J.F., White, H.R. \&, Pandina, R.J. (2008). Risk for excessive alcohol use and drinking-related problems in college student athletes. Addictive Behaviors, 33(12), 1546-1556. 